\title{
Marx e os povos sem história
}

Marx and the nonhistoric peoples

\begin{abstract}
We argue that Marx's statements on the non-historicity and stagnation of the oriental world does not represent a theoretical compromise with a supposedly innate superiority of the Europeans. Firstly, we present Asiatic Mode of Production according to Marx. Then, we argue that "Asiatic societies" are characterized by perpetuation of its endogenous economic structures which contrasts with the intense dynamism of capitalism. Further we show that "Oriental" societies are capable of endogenous capitalist development as soon as their archaic economic structures has been destroyed by capitalism. At last, we point that Marx's statements on Asiatic Mode of Production and "non-historic peoples" must be analyzed in the light of his general theory of progress and uneven historical development.
\end{abstract}

\section{Keywords}

Marx, theory of history, Asiatic mode of production.

JEL Codes B14, N00, P50.

\author{
André Guimarães Augusto (1) \\ Flávio Miranda (2) \\ Hugo F. Corrêa ${ }^{(3)}$ \\ (1) Universidade Federal Fluminense \\ (2) Universidade Federal Rural do Rio de Janeiro \\ (3) Universidade Federal Fluminense
}

\section{Resumo}

Argumentamos nesse artigo que as afirmações de Marx sobre a não historicidade e a estagnação do Oriente não representam compromisso teórico com uma suposta superioridade inata dos europeus. Primeiramente, apresentamos as características do Modo de Produção Asiático segundo Marx. $\mathrm{Na}$ seção seguinte, argumentamos que as "sociedades asiáticas" são caracterizadas por Marx pela perpetuação endógena de suas estruturas econômicas, que contrasta com o intenso dinamismo capitalista. Mostramos ainda que Marx observa que as sociedades "orientais" são capazes de desenvolvimento capitalista endógeno, tão logo as antigas estruturas econômicas tenham sido destruidas pelo capitalismo. Por fim, apontamos que as afirmações de Marx sobre Modo de Produção Asiático e "povos sem história" devem ser analisadas à luz de sua teoria geral do progresso $e$ do desenvolvimento histórico desigual.

\section{Palavras-chave}

Marx, teoria da história, modo de produção asiático.

Códigos JEL B14, N00, P50. 


\section{Introdução}

Em "The Future Results of British Rule in India", escrito em 22 de julho de 1853, Marx se refere à Índia como não tendo história. $\bigcirc$ autor inclui a Índia no que ele denominará mais tarde de Modo de Produção Asiático, no qual a ausência de história seria uma expressão de seu caráter estagnado, de sua imutabilidade. Mas qual o sentido real dessa estagnação na concepção marxiana? Alguns autores como Said (2007) afirmam que se trata de uma hipótese eurocêntrica de Marx. De acordo com essa interpretação as afirmações de Marx sobre o Oriente, e sobre as sociedades não europeias de um modo geral, são enviesadas por suas fontes europeias e seus preconceitos característicos. Adicionalmente, vê-se em outras interpretações críticas que atribuem o uso do termo não-histórico por Marx como uma repetição acrítica de Hegel, isto é, assim como Hegel, Marx advogaria uma superioridade ontológica da Europa. ${ }^{1}$

No presente artigo, argumentaremos que as afirmações de Marx sobre a não-historicidade e o caráter estagnado do Oriente não representam um compromisso teórico com uma suposta superioridade inata dos povos europeus, mas, ao contrário, deve ser analisada tendo em vista as tendências ontológicas do processo de desenvolvimento tal como capturadas pelo autor. Para isso, primeiramente apresentaremos as características do modo de produção asiático nos trabalhos de Marx. Na seção seguinte, tentaremos mostrar que as "sociedades asiáticas" são caracterizadas por Marx a partir da perpetuação endógena de suas estruturas econômicas, e que essa estabilidade contrastaria com o intenso dinamismo econômico do capitalismo. Mas isso não entraria em contradição com a ideia de que as sociedades "orientais" são capazes de um desenvolvimento endógeno próprio, uma vez que as antigas estruturas econômicas tenham sido destruídas pelo capitalismo imposto pelos países europeus.

$\mathrm{Na}$ seção final, será argumentado que a superioridade relativa das sociedades capitalistas europeias se restringe a seu dinamismo econômico, mas que essa dimensão nem esgota o conjunto de problemas que cerca a noção de progresso histórico, nem é suficiente para afirmar a superioridade europeia frente às comunidades "asiáticas". Argumentaremos ainda que as

1 Cf., por exemplo, Aricó (1982). Embora traçando um perfil mais detalhado dos supostos ascendentes intelectuais de Marx, tal crítica aparece também, por exemplo, em Anderson (2016, p. 524-528). 
afirmações de Marx sobre o Modo de Produção Asiático e os "povos sem história" devem ser analisadas à luz de sua teoria geral do progresso e do desenvolvimento histórico desigual das estruturas sociais.

\section{Marx e a caracterização do modo de produção asiá- tico}

Marx apresentou pela primeira vez os elementos sobre a especificidade dos modos de produção fora da Europa Ocidental em alguns artigos escritos para o New York Daily Tribune sobre o domínio britânico na Índia. Nesses artigos, Marx assinala que nas sociedades orientais a questão econômica decisiva era o provimento de obras públicas pelo Estado. A centralização de algumas funções econômicas pelo Estado seria um resultado das condições geográficas que levariam ao uso do trabalho em larga escala para a irrigação na agricultura. ${ }^{2}$ Ao lado da centralização estatal haveria a união da agricultura e da manufatura familiar e o comércio disperso em pequenos centros. ${ }^{3}$ Dessa forma, o sistema de aldeias seria resultado das funções econômicas governamentais e da união da agricultura e manufatura familiar. Uma consequência do sistema de aldeias seria o "despotismo oriental", no qual haveria um governo central acima das aldeias e com completo domínio sobre elas. Ao mesmo tempo, outro resultado desse sistema seria a "vida estagnada e vegetativa" do Oriente. O isolamento das aldeias e seu "equilíbrio por repulsão mútua" levaria à ausência de história na Índia: a história indiana seria então uma sucessão de invasões em uma sociedade passiva que permaneceria imutável.

No artigo "Chinese affairs", de 1862, Marx ainda generalizaria essas características para todas as sociedades orientais. Nesse artigo, Marx escreve que "os impérios orientais demonstram constante imobilidade em sua substrutura social, com uma mudança incessante nas pessoas e clãs que ganham o controle da superestrutura política". ${ }^{4}$

A questão da forma de propriedade no Oriente é também tratada por Marx nos Grundrisse. ${ }^{5}$ Ali, porém, ele assinala que o fator decisivo nas so-

2 Cf. Marx; Engels, 1979, v. 12, p. 127.

3 Ibid., p. 128.

4 Ibid., p. 216-217.

5 Cf. Marx, 2011. 
ciedades orientais foi o sistema de propriedade comunal organizado por aldeias autossuficientes. Em contraste com as afirmações dos artigos sobre a Índia, a ênfase recai agora sobre a propriedade comunitária das aldeias, da qual resultaria o governo centralizado. A unidade da propriedade comunitária seria centralizada no rei e nos deuses, com as comunidades aldeãs tendo apenas a posse da terra. Consequentemente, não haveria propriedade privada nesse sistema. A ausência de propriedade privada e a unidade da comunidade no governo central seriam, portanto, as chaves para entender a forma asiática de propriedade.

Por outro lado, como as sociedades orientais são apresentadas como sociedades rurais, as cidades aparecem apenas como local de comércio ou da troca do excedente produzido pelas comunidades aldeãs. As cidades, portanto, não teriam uma produção independente. $O$ ponto central nos Grundisse é que Marx assinala uma característica que estava ausente nos artigos do New York Daily Tribune, a apropriação do excedente das comunidades aldeãs pelo governo central. Esse excedente era apropriado pela pessoa do rei e dos sacerdotes dos templos, sob a forma de produto ou diretamente como trabalho.

Alguns anos antes da redação dos Grundrisse, Marx já havia notado a relação entre a religião e a extração de excedente em alguns artigos sobre o Império Otomano. Nesses artigos Marx afirma que "o Estado Turco, como todos os Estados Orientais, é fundado na mais íntima conexão, ou poderíamos quase dizer na identidade do Estado e do Templo, da Política e da Religião" (Marx; Engels, 1979, v. 13, p. 71). Marx também observa que no Império Otomano, os não muçulmanos deveriam pagar tributo para os muçulmanos. A religião dos povos conquistados era mantida, mas o caráter hierárquico das relações entre sacerdotes muçulmanos e ortodoxos, e também entre sacerdotes ortodoxos, "tinha alto preço". É possível inferir que o caráter despótico dos estados orientais é atenuado nesse artigo, uma vez que a subjugação dos gregos ortodoxos é feita somente pelo pagamento de tributos. Esse despotismo atenuado reaparece em $O$ capital como será visto mais adiante.

Outro ponto desenvolvido nos Grundrisse em relação aos textos anteriores é a extensão da forma de propriedade "asiática" para sociedades não "orientais". As comunidades do México (Astecas) e do Peru (Incas) e os Celtas são incluídos, assim, na forma de propriedade asiática. Marx também menciona as comunidades eslavas como uma variedade da forma 
asiática de propriedade, mas não desenvolve sua especificidade ${ }^{6}$.

A extensão do campo geográfico da forma de propriedade asiática e as várias possibilidades de organização do trabalho, distinta no interior dessas sociedades, levou Marx a atenuar a identificação anterior entre a forma asiática de propriedade e o despotismo oriental. Marx nota que o trabalho nessas comunidades poderia ser organizado de duas maneiras. Na primeira, a coletividade aloca parcelas de terra para as famílias que trabalham nelas, sendo o trabalho coletivo realizado como um complemento do trabalho das famílias ou como forma de pagamento de tributo para o governo central. Outra possibilidade seria a realização do trabalho em forma diretamente comunitária. Diante disso, Marx nota que a forma de propriedade asiática poderia levar a formas de governos mais democráticas ou despóticas.

A atenuação do caráter despótico das sociedades "asiáticas", no entanto, não impede Marx de identificar a situação dos indivíduos nessas sociedades com uma escravidão generalizada. Devido à unidade entre agricultura e manufatura essas sociedades não teriam desenvolvido o mesmo tipo de escravidão que a Europa Ocidental. A despeito disso, Marx assinala que nas

6 Tanto Mandel (1968, p. 129-130) quanto Anderson são críticos com relação à extensão geográfica e temporal da categoria "modo de produção asiático" para além daquelas sociedades inicialmente analisadas pelos autores. Anderson (2016, p. 534-536), em particular, é direto ao qualificar essa extensão como equivocada e calcada em Marx: "Assim como a de moedas, a inflação de ideias só leva à sua desvalorização. Mas é no próprio Marx que se encontra a permissão para as sucessivas cunhagens de asiatismos". É preciso observar, contudo, que a seu juízo a categoria modo de produção asiático deveria ser rejeitada in totum e não apenas por essa razão, mas também por sua inadequação empírica e pela atribuição de um caráter 'estacionário' ao modo de produção asiático: "As tentativas modernas de construir uma teoria bem desenvolvida do 'modo de produção asiático' a partir dos legados dispersos de Marx e Engels - seja na direção do 'tribal-comunal' ou do 'hidráulico-despótico' - estão, portanto, essencialmente desorientadas. Subestimam tanto o peso da problemática anterior que Marx e Engels aceitaram [i.e., a influência que tiveram de Bernier, James Mill, Montesquieu, Hegel etc.] quanto a vulnerabilidade das poucas modificações que introduziram. (...) A distorção mais óbvia e gritante que resultou desse procedimento foi a persistente atribuição de um caráter 'estacionário' às sociedades asiáticas” (Ibid., p. 544). A avaliação que Anderson faz da categoria modo de produção asiático caminha, portanto, em sentido substancialmente oposto àquele que buscamos desenvolver aqui. A seu juízo a atribuição de um "caráter estacionário" às "sociedades asiáticas" é o símbolo maior de quanto Marx bebeu nas águas de seus predecessores burgueses, do quanto absorveu dos preconceitos de seu tempo e do quanto foi incapaz de observar e compreender as mudanças, a evolução efetiva, dessas formações sociais. Ao contrário, entendemos que essa "estacionaridade" pode ser compreendida não como uma marca do preconceito esgrimido contra o Oriente, não sendo igualmente incompatível à consideração das evidentes contradições e transformações internas em diversos planos da vida social. Seria impossível, dado o escopo do trabalho, discutir aqui a avaliação de Anderson nos planos teórico e empírico. Para um bom balanço do debate e uma refutação mais sistemática dos argumentos de Anderson, ver Augusto (2015). 
sociedades asiáticas, os indivíduos, sendo parte da terra, são propriedade da unidade central. Desse modo, o caráter estagnado e imutável do modo de produção asiático é reafirmado nos Grundrisse. Essa imutabilidade resultaria da ausência de autonomia dos indivíduos em relação à comunidade. Em outras palavras, o caráter estagnado do modo de produção asiático se deveria à ausência de propriedade privada.

Nos Grundrisse, o caráter estagnado do modo de produção asiático é atribuído também ao baixo desenvolvimento da divisão do trabalho, isto é, à união entre agricultura e manufatura. Essa unidade leva as comunidades aldeãs à autossuficiência e, dessa forma, a seu isolamento e repulsão recíproca se autoperpetuaria. Portanto, as sociedades asiáticas são apresentadas como incapazes de desenvolver endogenamente outras formas de propriedade.

Mais ou menos na mesma época da redação dos Grundrisse, Marx assinala o caráter estagnado das sociedades asiáticas também em uma série de artigos sobre a China no New York Daily Tribune. Em "History of the Opium trade" (1853), Marx se refere à China como um "império gigantesco, contendo quase um terço da raça humana, vegetando até o fim dos tempos" (Marx; Engels, 1979, v. 16, p. 16). Em "Trade with China" (1858), Marx observa que a estrutura econômica da China, "dependente da combinação da pequena agricultura com a indústria doméstica", é a mesma da Índia, pelo menos sob esse aspecto (Ibid., v. 16, p. 536).

Em $O$ capital, Marx adiciona outros elementos ao modo de produção asiático. A propriedade da terra ainda é vista como comunitária, com a observação de que a "forma da comunidade varia nas diferentes partes da Índia" (Marx, 2013, p. 431). Além disso, a autoperpetuação da divisão do trabalho nas comunidades fornece a explicação para a "imutabilidade das sociedades asiáticas" (Ibid., p. 432). Marx lista vários trabalhos administrativos e artesanais que são dependentes da produção das comunidades aldeãs. De acordo com Marx, a divisão do trabalho é reproduzida exatamente da mesma forma toda vez que a comunidade se expande.

Outro elemento do modo de produção asiático desenvolvido em $O$ capital é o modo de extração e apropriação do excedente das comunidades aldeãs. ${ }^{7}$ Nessa obra, o excedente é caracterizado como forma prototípica

7 Em O Capital o elemento central para a caracterização do modo de produção asiático passa a ser a estrutura da propriedade e o modo de extração do excedente. Deste modo a contestação de Anderson (2016) referente à não aderência empírica da 'hipótese hidráulica' do modo de produção asiático em várias situações se torna secundária. Do mesmo modo a existência de propriedade privada, apontada por Anderson, não invalida a caracterização do modo de 
da renda da terra que se funde com os tributos, sendo apropriado pelo Estado (Marx, 1987, p. 907). Marx aponta que o excedente era extraído ou diretamente na forma de trabalho ou, mais frequentemente, como produtos. Ele também adiciona elementos relacionados ao comércio de mercadorias no modo de produção asiático. As comunidades aldeãs não produziriam mercadorias devido ao seu caráter autossuficiente e à forma direta de extração do excedente (Ibid., p. 932). No entanto, o excedente seria comercializado pelos representantes do Estado (Ibid., p. 409).

É preciso notar aqui que Marx não entra em detalhes sobre a comercialização do excedente no modo de produção asiático. Marx apenas indica que, com a transformação do modo de extração do excedente da forma de trabalho para forma de produtos, a classe estatal passa a comercializar parte do excedente apropriado, o transformando em mercadoria. A comercialização do excedente visa ao consumo por parte dos representantes do Estado, de produtos que não são produzidos pela comunidade, ou seja, a produção permanece tendo por objetivo o valor-de-uso.

A questão do despotismo asiático também reaparece em $O$ capital, mas mais uma vez de forma atenuada. Ali, a questão é associada ao modo de extração do excedente. Marx observa que uma vez que as comunidades aldeãs têm a posse da terra, a forma como o trabalho organiza-se não está sujeita ao controle do Estado. No entanto, a extração de excedente depende da coerção extraeconômica, uma vez que as comunidades aldeãs não são proprietárias. Marx assinala que essa coerção extraeconômica é uma característica de todas as sociedades pré-capitalistas, nas quais a propriedade é dissociada da posse da terra.

A coerção extraeconômica no modo de produção asiático tem características específicas. Quando o excedente é apropriado pelos proprietários privados há uma dependência pessoal e uma subordinação dos produtores diretos. Mas no modo de produção asiático a coerção extraeconômica "não precisa assumir a forma mais dura que a observância e subordinação de todos ao Estado" (Marx, 1987, p. 907). Além disso, uma vez que o excedente é apropriado, predominantemente, sob a forma de produtos, "a coerção não se exerce mais com a brutalidade antiga" (Ibid., p. 912), isto é, quando o excedente era apropriado diretamente como trabalho.

produção asiático pela propriedade comunal como elemento central de sua reprodução. Para uma discussão mais detalhada sobre o conceito de modo de produção e o modo de produção asiático ver Augusto (2015). 
Assim, a despeito desses elementos adicionais ao modo de produção asiático, Marx ainda mantém o seu caráter estacionário em $O$ capital.

\section{Os "povos sem história" e o modo de produção capi- talista}

É recorrente na obra de Marx a identificação do caráter estagnado do modo de produção asiático, portanto. Nesta seção, interpretamos o que Marx quer dizer com tais referências à "estagnação" e à "vida vegetativa" do modo de produção asiático. A despeito do teor pejorativo desses termos, acreditamos que estes apenas possam ser compreendidos à luz da obra de Marx como um todo.

Como observação introdutória devemos notar, antes de mais nada, que o esforço teórico de Marx se volta, primordialmente, para a análise do modo de produção capitalista. Assim, as referências de Marx a modos não capitalistas de produção estão geralmente relacionadas "às origens e ao desenvolvimento do capitalismo" (Hobsbawm, 2011, p. 130). ${ }^{8}$ Ademais, seguindo o último Lukács (2012, p. 319), acreditamos que Marx estava preocupado com a constituição das condições necessárias para a emergência da sociedade capitalista, tendo sempre por pressuposto o entendimento rigoroso das condições gerais (ontológicas) do desenvolvimento no ser social. Isso significa que a tais observações subjaz uma concepção bastante específica de progresso. Segundo Lukács:

Hoje é moda ironizar ideias de progresso e utilizar as contradições que todo desenvolvimento necessariamente provoca, com a finalidade de desacreditar o progresso no plano científico, ou seja, de considerar o progresso, o desenvolvimento de um grau ontologicamente inferior a um grau ontologicamente superior, como um juizo de valor subjetivo (Lukács, 2012, p. 319).

Em segundo lugar, devemos notar que Marx oferece tratamento teórico muito sumário sobre a expansão geográfica do modo de produção capitalista. Tal análise estava fora do escopo de sua principal obra, $O$ capital,

8 Entendemos que, a esse respeito, há convergência entre esta leitura e a de Mandel: "Resta colocar todas essas considerações sobre o 'modo de produção asiático' no seu contexto concreto, isto é, na análise efetuada, por Marx, das condições históricas - mais abstratas - do impulso do capital e do capitalismo. Ter-se-á já então compreendido que, segundo o método dialético que ele usa com predileção nos Grundrisse, Marx não se demora sobre as 'formas que precedem a produção capitalista' senão para pôr em evidência, de maneira negativa, os fatores que, positivamente, conduziram ao desabrochamento do capital e do capitalismo na Europa" (Mandel, 1968, p. 140. Ver também a nota 34, p. 130, da mesma obra). 
como o próprio Marx admitia (Heinrich, 1997, p. 462). Podem ser encontradas, contudo, análises concretas sobre os resultados possíveis e observados da expansão geográfica do capitalismo em artigos de conjuntura, como visto. Nestes, porém, o tema principal é o da colisão entre sociedades regidas por modos capitalista e pré-capitalistas de produção. Em suma, podemos concluir que a abordagem de Marx sobre o modo de produção asiático é comparativa com o capitalismo. No entanto, é preciso advertir: Marx não faz história comparativa, mas comparações históricas.

Esse modo comparativo de análise é evidente no trecho dos Grundrisse conhecido como "Formas que precederam a produção capitalista". No texto, desde suas primeiras linhas (e em diversos outros momentos), Marx delimita o estudo dos pressupostos históricos do capital, no que diz respeito às relações de trabalho, como objeto da análise (Marx, 2011, p. 388). Mais especificamente, o autor estava interessado na maneira como a separação entre os trabalhadores e as condições objetivas da produção - que, junto ao advento da liberdade jurídica, conforma o momento necessário da transformação da força de trabalho em mercadoria, e, portanto, da própria produção capitalista - poderia ou não decorrer das legalidades imanentes a diferentes modos de produção. ${ }^{9}$ Ou seja, o modo de produção asiático é considerado apenas em vista da análise das características internas que teriam impedido o advento de tais condições, à diferença do feudalismo europeu, cujo desenvolvimento, como se pode dizer em retrospecto, desembocou no modo de produção capitalista. Em um desses momentos, em que seu objetivo se apresenta sem deixar espaço para dúvidas, diz Marx:

O que nos interessa aqui, antes de tudo: o comportamento do trabalho em relação ao capital, ou às condições objetivas do trabalho como capital, pressupõe um processo histórico que dissolve as diferentes formas em que o trabalhador é proprietário ou em que o proprietário trabalha. Sobretudo, por conseguinte: 1) dissolução do comportamento em relação à terra - território - como condição natural de produção, com a qual ele se relaciona como sua própria existência inorgânica (...). 2) Dissolução das relações em que ele figura como proprietário do instrumento. (...) 3) Incluído em ambos está o fato de que ele tem em seu poder, antes da produção, os meios de consumo necessários para viver como produtor (...). 4) Por outro lado, dissolução na mesma medida das relações em que os próprios trabalhadores (...) ainda fazem parte diretamente das condições objetivas de produção e são apropriados enquanto tais - ou seja, são escravos ou servos (Ibid., pp. 408-409, grifos do original).

9 Cf. Marx, 2011, p. 401 
Marx ocupa-se, na maior parte do texto, com a análise de três modos de produção, considerados em elevado nível de generalidade: a forma oriental; a forma antiga; e a forma germânica. Nessas três formas, os indivíduos "se relacionam às condições objetivas do trabalho como sendo suas [próprias] condições", um comportamento, todavia, mediado pela existência, "mais ou menos historicamente desenvolvida e modificada, do indivíduo como membro de uma comunidade" (Ibid., p. 397, adendo do editor e grifos do autor). As diferenças entre essas formas de reprodução material, nas quais estava posta a unidade entre trabalhadores e condições objetivas do trabalho, devem-se em parte às "condições econômicas sob as quais" essas diferentes formações se relacionam "à terra como proprietária" (Ibid., p. 398). Por sua vez, a forma da apropriação da terra pelo trabalho depende tanto de fatores geoclimáticos, quanto de fatores sócio-históricos como a relação (hostil ou não) com outras comunidades, migrações etc.

Como característica ontológica do desenvolvimento histórico no ser social, a dialética interna a toda forma de reprodução social, isto é, sua forma necessariamente contraditória, implica uma tendência à dissolução de seus próprios pressupostos. "Em todas essas formas, o fundamento do desenvolvimento é a reprodução das relações pressupostas do indivíduo à sua comunidade (...), desenvolvimento que, por conseguinte, é por princípio limitado, mas que superado o limite, representa decadência e desaparecimento" (Ibid., pp. 398-399, grifos do autor). Ou seja, a partir de certo ponto essa forma de reprodução social torna-se incompatível com seus fundamentos, o que põe as condições necessárias (mas não necessariamente suficientes) para sua superação.

Como todos os modos pré-capitalistas de produção, o modo de produção asiático tem por base a preservação de sua estrutura econômica. No entanto, como já notamos, os limites à reprodução no modo de produção asiático são bastante elásticos, dada sua peculiar constituição interna.

Vimos que a divisão do trabalho, as formas de propriedade e os modos de extração do mais-trabalho resultam do isolamento e perpetuação endógena dessa estrutura econômica. A preservação por tradição e hereditariedade são os princípios fundamentais dessas sociedades. Na Índia o modo de produção tinha por base o sistema de castas, com sua divisão hereditária do trabalho. Marx observa que esse sistema constituía um "impedimento decisivo para o progresso da Índia e para a força da Índia" (Marx; Engels, 1979, v. 12, p. 221). 
Termos como "imutabilidade" e "estagnação", usados por Marx em sua caracterização das sociedades asiáticas, não são, todavia, incompatíveis como algum tipo de transformação nessas formas de reprodução social. Tal transformação, contudo, corresponde a um "equilíbrio dinâmico", um movimento no qual as contradições motrizes levam à preservação, em vez de mudança constante, ou, nos termos que Marx usou para referir-se à Índia, um "equilíbrio por mútua repulsão". De modo similar, ao analisar a Rebelião Taipei na China, Marx notou que os rebeldes "não estão atentos para qualquer tarefa que não seja a mudança dinástica" e que após dez anos "eles destruíram tudo e produziram nada" (Marx; Engels, 1979, v. 19, p. 217).

Marx contempla a existência de classes, a dos produtores diretos e dos representes do Estado, no modo de produção asiático. Sendo extraído excedente sob coerção direta, há também luta de classes. A "imutabilidade" ou estagnação não pode ser explicada pela ausência de luta de classes, mas pelas condições em que essa se dá e que determinam o seu resultado. Em outras palavras, as "revoluções" tradicionais nas sociedades asiáticas representavam um meio para a preservação, não sua derrota.

Se a forma da reprodução social no modo de produção asiático pode ser representada como um movimento de estabilidade dinâmica, a superação dessa forma mesma pode ser acionada por um fator externo. Tal resultado era antevisto por Marx em suas análises da colisão entre as estáveis sociedades asiáticas e a sociedade na qual "tudo que era sólido e estável se desmancha no ar" (Marx; Engels, 2010, p. 43).

Olhando deste outro ângulo para o já citado artigo "The Future Results of Britih Rule in India", vemos que Marx foi capaz de perceber que a política colonial era o "resultado orgânico da totalidade do sistema de produção tal qual este se constitui atualmente" (Marx; Engels, 1979, v. 12, p. 222). Ou seja, a dominação britânica sobre a Índia deve ser vista como resultado das leis imanentes ao modo de produção capitalista que impeliam à expansão geográfica das relações mercantis. Assim, ao se questionar sobre "como pôde a supremacia britânica estabelecer-se na Índia?", Marx aponta para o encontro entre dois modos de produção distintos, com distintas dinâmicas reprodutivas. O capitalista repousa "no domínio supremo do capital", cujo processo de acumulação é "essencial para a existência do capital como poder independente", isto é, em um intenso dinamismo econômico; enquanto o processo reprodutivo no modo de produção asiático 
baseava-se na preservação da estrutura econômica. O resultado necessário desse encontro tinha de ser a dominação capitalista.

Deve-se notar que o desenvolvimento do capitalismo tem por momento fundante a superação dos modos de produção arcaicos, isto é, sua dominação efetiva-se pela destruição dos modos precedentes de produção. Ademais, a inevitabilidade da conquista britânica era reforçada pela ausência de uma unidade política interna consolidada e pelo isolamento entre as comunidades aldeãs, que tornavam a Índia suscetível à dominação estrangeira. As condições necessárias para um passo adiante na história do país, defendia Marx, seriam postas, contudo, pela própria dominação britânica.

Percebe-se que uma noção de progresso subjaz a essas considerações do autor. A tendência principal do desenvolvimento humano é o progressivo, embora nunca plenamente completo, afastamento das barreiras naturais. Esse é um processo de crescente socialização dos seres humanos, ou seja, um curso no qual a vida humana adquire um caráter cada vez mais predominantemente social. De acordo com Lukács:

Não há dúvida de que temos aqui um processo de desenvolvimento; e também se pode dizer que, no plano puramente ontológico, é um progresso o fato de que essa nova forma do ser social consiga, no curso de seu desenvolvimento, realizar cada vez mais a si mesmo, ou seja, explicitar-se em categorias cada vez mais independentes e conservar as formas naturais apenas de um modo que crescentemente as supera. Nessa constatação ontológica do progresso não está contido nenhum juizo de valor subjetivo. Trata-se da constatação de um estado de coisas ontológico, independentemente de como ele seja avaliado depois. (Pode-se aprovar, deplorar etc. o "afastamento da barreira natural") (Lukács, 2012, p. 320).

O desenvolvimento das forças produtivas representa a condição para esse progresso. Ao longo dessa corrente principal de desenvolvimento há um gradual, embora não linear, desenvolvimento material no âmbito do ser social. Esse progresso, necessariamente contraditório, engendra, com o advento da sociedade burguesa, a possibilidade, mas apenas a possibilidade, da superação de todas as formas de dominação social e, portanto, do livre desenvolvimento humano. ${ }^{10}$

Marx argumenta que o modo de vida nas comunidades indianas àquela época correspondia a um estado social no qual os seres humanos estavam submetidos a circunstâncias exteriores, o que achava reflexo numa "brutalizante adoração da natureza" (Ibid., p. 132). Nas circunstâncias que então vigoravam na Índia, de senhor da natureza, o ser humano "caía de joelhos

10 Cf. Marx; Engels, 1979, v. 12, p. 222. 
em adoração à Kanuman, o macaco, e a Sabbla, a vaca" (Ibid.). Não restam dúvidas de que se, por um lado, "a religião é o suspiro da criatura oprimida" (Marx, 2013, p. 151), os cultos pagãos representavam um estágio materialmente menos desenvolvido, cujos ritos expressam tal acentuada subsunção às determinações naturais. Sob esse critério objetivo, é inegável que a dominação britânica continha também um elemento progressista. Em outras palavras, entre os resultados da dominação britânica consta a possibilidade do desenvolvimento da Índia no sentido ontológico acima delimitado, isto é, do afastamento das barreiras naturais, a crescente socialização que faculta a quebra do isolamento de comunidades locais e, portanto, o progresso no que diz respeito ao reconhecimento do gênero humano, como discutiremos na próxima seção.

Nesse sentido, Marx compreendia que a conquista britânica da Índia, apesar de destruidora, seria potencialmente regeneradora (Marx; Engels, 1979, v. 12, p. 218). Segundo o autor, a dominação britânica levou à Índia a condição do progresso, o desenvolvimento das forças produtivas. Segundo Marx: "o sistema de linhas férreas tornar-se-á na Índia o verdadeiro precursor da indústria moderna" (Ibid., p. 220). O sistema ferroviário produziria um desenvolvimento necessário das forças produtivas pelo consequente desenvolvimento das trocas internas, por possibilitar incrementos na produtividade agrícola e pela necessidade da implantação de uma indústria acessória ao transporte ferroviário.

O principal efeito do desenvolvimento nas forças produtivas possibilitado pela dominação britânica, contudo, seria a quebra do isolamento das comunidades aldeãs indianas. Marx aponta que tal isolamento seria "a lei primordial de sua estagnação". Tal acontecimento levaria a uma diversificação das relações sociais na Índia, enriquecendo-as em variedade e escopo. Assim, a quebra do isolamento das comunidades aldeãs representa um avanço a um patamar superior de socialidade.

Deve-se atentar para o fato de que a burguesia estava involuntariamente oferecendo no início da década de 1850 tão somente as condições materiais para o progresso no sentido acima explicitado. A regeneração da Índia, reconhece Marx, dependeria "não apenas do desenvolvimento das forças produtivas, mas de sua apropriação pelo povo" (Ibid., p. 221). Os britânicos não poderiam manter o controle das forças produtivas desenvolvidas na Índia unicamente sob seus interesses. As condições materiais teriam de cair, de uma forma ou de outra, nas mãos dos indianos. Em outras palavras, 
o status colonial da Índia não era condição eterna para seu desenvolvimento, mas resultado da expansão capitalista que fez com que emergissem possibilidades inteiramente novas para o desenvolvimento do país.

A estagnação e a vida vegetativa, portanto, não eram vistas como resultados de fatores étnicos ou naturais dos indianos ou dos "povos orientais". Marx sugere que, uma vez que o capitalismo fora levado ao oriente, deveria seguir aí uma rota própria de desenvolvimento. No entanto, se a condição colonial era meio para a destruição da "vida estacionária e vegetativa", era também um impedimento para a efetivação dos potenciais emancipatórios presentes em sociedades "asiáticas".

A apropriação dos frutos do desenvolvimento material pelo povo indiano pressupunha uma organização popular que fosse capaz de realizar uma revolução social para suplantar a burguesia inglesa no país, o que poderia acontecer de duas formas possíveis: ou na Grã-Bretanha o proletariado derrotaria a classe dominante; ou os próprios indianos organizados "tornar-se-iam fortes o suficiente para livrarem-se do jugo inglês" (Ibid.). Deve-se atentar para o fato de que, em muitos dos textos em questão, Marx aponta que a dominação colonial é não apenas uma condição insuportável, como põe ela mesma os meios para sua superação. Ao comentar a revolta dos Cipaios de 1857, também na Índia, o autor nota que "há algo de retribuição na história humana; e é uma regra da retribuição histórica que seus instrumentos sejam forjados não pelo ofendido, mas pelo próprio ofensor" (Marx; Engels, 1979, v. 15, p. 353). Em suma, a expansão geográfica do capitalismo também leva o espectro da revolução às sociedades "asiáticas". A libertação nacional, contudo, não seria uma condição suficiente para a efetivação de todas as potencialidades contidas no desenvolvimento das forças produtivas. Segundo Marx, a burguesia desenvolve as forças produtivas e nada mais. Assim, a verdadeira apropriação das forças produtivas pelos produtores e sua transformação em meio para a emancipação humana requer a libertação do jugo burguês.

Temos aqui um ponto fundamental nas análises de Marx sobre sociedades "asiáticas" e sua relação com sociedades capitalistas ocidentais. A luta dos povos contra a dominação estrangeira nunca era considerada à parte da luta de classes. A primeira sem a segunda apenas levaria à expansão do processo de acumulação de capital e da dominação burguesa ao redor do mundo. A segunda poderia, contudo, ter a primeira como condição um tipo de pensamento estratégico recorrente em Marx, desde a rebelião 
Taipei na China, no final dos anos de 1850, até sua consideração sobre o movimento narodnik contra o Czar na Rússia, em princípios dos anos de 1880 (Marx; Engels, 2013, pp. 80-115).

É patente o otimismo de Marx sobre a formação de um forte movimento de libertação nacional na Índia, o que de fato ocorreu na revolta dos Cipaios ${ }^{11}$. Para o autor, aquilo o que os britânicos consideravam "um motim militar é na verdade uma verdadeira rebelião nacional" (Marx; Engels, 1979, V. 15, p. 316). Contrariamente à representação dos indianos como um povo naturalmente passivo, Marx assevera que "falar sobre a apatia dos indianos ou mesmo sobre sua simpatia pela dominação britânica não faz o menor sentido" e que seria "um quid pro quo curioso esperar que uma rebelião indiana assumisse o caráter de uma revolução europeia" (Ibid., p. 329).

Contudo, a revolta dos Cipaios não foi vitoriosa, o que forçou Marx a reconhecer textualmente, em 1882, que o imperialismo britânico "não impulsionou o povo indiano para frente, mas o empurrou para trás" (Marx, 2013, p. 108). Suas análises sobre os resultados da dominação britânica acompanharam o processo histórico objetivo (assim como mudaram significativamente com a evolução de sua compreensão sobre aquelas formações sociais, como vimos).

Contudo, o fato de que, até aquele momento, a regeneração da Índia não tivera lugar não contradiz a noção ontológica de progresso social sempre presente na teoria marxiana. Tal arranjo apenas denota como o desenvolvimento social depende de condições que podem ou não se efetivarem. O progresso social resulta de contradições reais, do conflito entre forças produtivas e relações sociais de produção e, fundamentalmente, das lutas de classes. Em outras palavras, a História em Marx não é uma sucessão mecânica de fases predeterminadas, mas uma corrente de desenvolvimento humano que segue um curso não linear, como argumentaremos na próxima seção.

Antes, retomemos o argumento central deste artigo para apresentar algumas notas conclusivas a esta seção. Em primeiro lugar, observemos que quando Marx refere-se repetidamente à vida estagnada no modo de produção asiático ele raramente classifica tais sociedades como "não-históricas". Tal referência pode ser encontrada apenas no artigo "The Future Results of Britih Rule in India". Contudo, há outra passagem relativamente nação britânica em 1857-1859" (Marx; Engels, 1979, v. 15, p. 315). 
conhecida de Marx sobre um "povo sem história". Nesta se refere, entretanto, a uma nação europeia, em vez de a uma sociedade "asiática".

Em um trecho de A ideologia alemã, de 1845-1846, ao comentar a relação entre a história da humanidade e o desenvolvimento das forças produtivas e das formas de intercâmbio, Marx apresenta uma avaliação da situação da Alemanha de Frederico Guilherme IV:

Mas é claro, também, que na Alemanha é impossivel escrever tal história [da indústria e das trocas], pois aos alemães faltam não apenas a capacidade de concepção e o material, como também a "certeza sensivel", e do outro lado do Reno não se pode obter experiência alguma sobre essas coisas, pois ali já não ocorre mais nenhuma história (Marx; Engels, 2007, p. 34, grifos nossos).

Aqui, como no caso da Índia, Marx refere-se apenas à carência de um intenso dinamismo econômico. Haveria uma contínua preservação da estrutura econômica praticamente da mesma forma em que existiu por séculos, sem a transformação de sua base social e da relação das diferentes comunidades com o governo central. A despeito disso, essa ausência de história no sentido do desenvolvimento econômico não significa de modo algum, em Marx, ausência de evolução em outras formas de objetivação social.

Também é possível concluir que o uso da noção de "povos sem história" por Marx não constitui uma adição a seu corpo categorial fundamental, sendo, antes, uma inversão irônica e materialista do sentido que ela possui em Hegel. Pois enquanto para Hegel o sentido da expressão "povos sem história" é a ausência (e a impossibilidade absoluta) de desenvolvimento do Espírito, para Marx ela parece se referir a uma ausência relativa de dinamismo econômico. ${ }^{12} \mathrm{E}$ isso para não mencionar os vários casos em que Marx afirma ser o grau de desenvolvimento e o "espírito" dos povos sem história ainda superiores àqueles das sociedades capitalistas. Esse ponto será explorado com mais cuidado a seguir.

12 Devemos passar ao largo aqui de um aspecto do debate sobre a utilização da noção de povos sem história, qual seja a teoria de que a aceitação acrítica da noção hegeliana de povos sem história em Marx se deva a uma influência deletéria de Engels. Uma das principais referências a esse respeito é a tese de Roman Rosdolsky (1991), que se ampara sobretudo no conteúdo publicado na Nova Gazeta Renana, entre 1848 e 1849, segundo ele com Engels à sua frente como editor-chefe. Naquele contexto de grande ebulição social na Europa, Rosdolsky entende que o "otimismo revolucionário" de Engels (e de Marx) sobre as possibilidades de vitória os conduziu a assumir o lado de opressores e os cegou para os problemas do nacionalismo e (consequentemente) da opressão de certos povos (Ibid., p. 131). Não obstante se reconheça aqui a insuficiência desta nota para dar conta de um debate tão acalorado, gostaríamos de indicar que propomos neste artigo uma forma alternativa de conceber como e por que a noção de povos sem história é utilizada pelos autores de modo mais coerente com o conjunto do corpo teórico que eles nos legaram. 


\section{Progresso, desenvolvimento desigual e os "povos sem história"}

Como tentamos argumentar anteriormente, tomar o uso de Marx de expressões como povos "sem história" ou "estagnados" como sinônimo de um preconceito contra sociedades "asiáticas" é incompatível com a perspectiva marxiana de história e progresso. E não há categoria que explicite melhor essa questão que a de desenvolvimento desigual.

Hoje, quando se fala em desenvolvimento desigual a maioria dos marxistas geralmente lembra-se das diferenças existentes entre países (ou comunidades). A questão, nesse sentido, seria a da criação de um espaço heterogêneo pela expansão geográfica do capitalismo, no qual as condições de produção e consumo evoluem com ritmos diversos. ${ }^{13}$ Ademais, se poderia acrescentar que isso ocorre porque as nações menos desenvolvidas combinam elementos típicos da produção capitalista com outros, pré-capitalistas.

E não é difícil entender por que a ênfase recai nesses aspectos sempre que se menciona o desenvolvimento desigual - especialmente se lembramos que os mais destacados estudos a esse respeito se derivam dos trabalhos de Lênin e Trotsky. Tanto Lênin quanto Trotsky, na virada do século XX, se preocuparam com a forma particular de desenvolvimento do capitalismo na Rússia e com as consequências do imperialismo no plano mundial. No que tange à questão do imperialismo, Lênin propõe a ideia de uma "estratificação hierárquica" no mundo, que passaria a se dividir em "potências coloniais", "colônias" e nações "semicoloniais" ou "dependentes". Estas seriam "formas transitórias de dependência estatal", ainda sob influência das potências coloniais mas nas quais o capitalismo avançava rapidamente. ${ }^{14}$ No entanto, nem mesmo o completo desenvolvimento capitalista nivelaria todas as nações - aliás, justo o oposto, como argumentaria firmemente Lênin em sua polêmica contra a teoria do ultraimperialismo de Kautsky.

Igualmente importante é o argumento que Lênin desenvolve a respeito da preservação de relações sociais pré-capitalistas no curso do desenvolvi-

13 Nesse sentido, a categoria desenvolvimento desigual é tomada, por vezes, num sentido muito restrito, como a simples tendência do capitalismo a aumentar a disparidade do desenvolvimento mundial.

14 Lênin, 2011, p. 212. 
mento capitalista. Em seu trabalho seminal, $O$ desenvolvimento do capitalismo na Rússia, Lênin escreve:

Quanto ao problema da lentidão ou rapidez do desenvolvimento do capitalismo na Rússia, tudo depende daquilo com que se compare esse desenvolvimento. Se se compara a época pré-capitalista da Rússia com o seu periodo capitalista (e é justamente essa comparação que deve ser feita para a correta solução do problema), é forçoso reconhecer que, sob o capitalismo, a nossa economia nacional se desenvolve muito rapidamente. Mas se a comparação é feita entre esse ritmo de desenvolvimento e aquele que seria possivel sob o nivel atual da técnica e da cultura, deve-se, em geral, reconhecer que esse desenvolvimento do capitalismo na Rússia é realmente lento. E não poderia ser diferente: nenhum outro país capitalista conserva tantas instituições antigas, incompatíveis com o capitalismo, retendo o seu desenvolvimento e agravando infinitamente a situação dos produtores, que "sofrem tanto pelo capitalismo como pelo seu insuficiente desenvolvimento" (Lênin, 1983, p. 375, grifos nossos).

Essa ideia seria mais bem desenvolvida por Trotsky, em sua formulação da "lei do desenvolvimento desigual e combinado" da história:

A desigualdade do ritmo, que é a lei mais geral do processo histórico, manifesta-se com maior vigor e complexidade nos destinos dos países atrasados. Sob a força das necessidades exteriores, a vida retardatária é obrigada a avançar por saltos. Desta lei universal de desigualdade dos ritmos decorre uma outra lei que, na falta de denominação mais apropriada, pode-se chamar lei do desenvolvimento combinado, no sentido da reaproximação das diversas etapas, da combinação de fases distintas, da amálgama de formas arcaicas com as mais modernas. Na falta desta lei, tomada, bem entendido, em todo o seu conteúdo material, é impossivel compreender a história da Rússia, como, em geral, de todos os países chamados à civilização em segunda, terceira ou décima linha (Trotsky, 1950).

Trostky sustenta que a percepção da existência dessa lei seria suficiente para debelar compreensões esquemáticas acerca da história, que a entendem como uma sucessão predeterminada de modos de produção. Pois, segundo essa lei, seria possível que uma nação atrasada adquirisse elementos da mais desenvolvida e fosse lançada à frente.

Assim, no decorrer do século XX, pelas mãos de Lênin e Trotsky, a categoria desenvolvimento desigual passaria a ser imediatamente associada à questão das disparidades de renda entre nações, ou mais precisamente das disparidades entre suas forças produtivas e relações de produção. E essa é uma dimensão do problema, mas é preciso notar que essa não se trata de sua única dimensão. Por exemplo, nas notas marxianas presentes na inacabada Introdução de 1857, publicadas junto aos Grundrisse, encontramos uma menção explícita à questão. Ali, tratando da análise da "produção", Marx enumera alguns pontos que não deveriam ser esquecidos, um deles sendo: 


\begin{abstract}
A relação desigual do desenvolvimento da produção material com, por exemplo, o desenvolvimento artístico. Não conceber de modo algum o conceito de progresso na abstração habitual. Com a arte moderna etc., essa desproporção não é tão importante nem tão difícil de conceber quanto [a que ocorre] no interior das próprias relações prático-sociais. Por exemplo, a cultura [Bildung]. Relação dos Estados Unidos com a Europa. Mas o ponto verdadeiramente difíil de discutir aqui é o de como as relações de produção, como relações jurídicas, têm um desenvolvimento desigual. Em consequência disso, p. ex., a relação do direito privado romano (nem tanto o caso no direito penal e no direito público) com a produção moderna (Marx, 2011, p. 62).
\end{abstract}

Não obstante seu estilo fragmentário, é possível perceber na passagem que Marx tratou do problema do desenvolvimento desigual considerando a relação entre produção material e outras esferas (outros complexos) da vida social, como a arte, a cultura e o direito. Mesmo não tendo elaborado ali mais adequadamente essa ideia, sua posição é um pouco mais inteligível quando, pouco adiante, ele explica por que seria impossível que a arte grega se desenvolvesse em tempos modernos - embora continuasse sendo, em certa medida, o "modelo" para as artes - posto que ela pressupõe a mitologia grega e, portanto, um conhecimento limitado do mundo, uma perspectiva ingênua com relação à natureza etc. ${ }^{15}$

Não há espaço aqui para debater a questão em maiores detalhes, contudo concorda-se com Lukács quando este sugere que a questão é analisar em que medida certas condições objetivas de produção, o que poderíamos chamar de tendência geral do desenvolvimento, são favoráveis ou desfavoráveis ao desenvolvimento da arte e de certos gêneros artísticos etc. Nesse sentido, é bastante interessante a observação de Lukács (2012, p. 392) de que "o desenvolvimento capitalista, pelas razões aqui indicadas por Marx, trouxe consigo, por um lado, um florescimento musical jamais ocorrido, mas, por outro, representou para a arquitetura a fonte de uma problemática crescente e cada vez mais difícil de solucionar".

Depreende-se daí que o entendimento de Lênin e Trotsky a respeito do desenvolvimento desigual, mesmo se correto, é incompleto, porque lida apenas com o que poderíamos chamar de seu aspecto econômico-geográfico. Desde uma perspectiva mais ampla, poderíamos dizer que a interpretação aqui alinhavada busca sublinhar que a realidade é composta por uma série de estruturas complexas (totalidades parciais) em interação umas com as outras; e que, assim sendo, é sempre possível que o desenvolvimento progressivo num desses complexos (por exemplo, a força produtiva 
do trabalho) se faça acompanhar de atrasos em outros complexos (por exemplo, a arte ou o direito etc.). Nesse sentido mais amplo, a categoria desenvolvimento desigual diz respeito, portanto, a esse "descasamento" na evolução social. ${ }^{16}$

Um problema fundamental que emerge quando se defende essa forma de tratar a categoria desenvolvimento desigual é em que medida a noção de progresso ainda se aplicaria à história. Em outras palavras, se se admite que a história não pode ser representada em uma única linha (reta), não se tornaria impossível também afirmar a existência de um desenvolvimento objetivo? Como já argumentamos anteriormente, acreditamos que essa impossibilidade não existe. Embora o desenvolvimento histórico esteja sujeito à desigualdade, ainda assim continua a existir a tendência principal de um desenvolvimento objetivo, em uma palavra, um progresso. De modo sintético, tentaremos seguir a indicação de Lukács (2012), segundo a qual há três indicativos desse desenvolvimento objetivo na história humana. ${ }^{17}$

O primeiro é o desenvolvimento das forças produtivas, o fato de que hoje é possível produzir e reproduzir as condições materiais da vida humana em tempo mais curto. O segundo, ao qual já nos referimos na seção anterior, é o que Lukács (seguindo Marx) chamou de "recuo das barreiras naturais" - significando que a humanidade se afasta progressivamente de suas necessidades meramente biológicas, criando para si um mundo predominantemente dominado por categorias sociais. É claro que, como seres humanos nunca deixaram (e, salvo melhor juízo, nunca deixarão) de ser também formas de vida orgânica, esse recuo das barreiras naturais nunca pode ser completo. Ainda assim, entre nossas necessidades naturais e sua

16 Essa ideia de desenvolvimento desigual entre complexos sociais nos permitir também tomar em consideração em sentido dialético a metáfora da correspondência entre "base" e "superestrutura". Assim entendida a questão, deve-se compreender que a "base" é refletida na "superestrutura", mas isso não significa que ambas compartilhem as mesmas determinações, a mesma existência. Como Hegel (2008, p. 140) nota em sua dialética da essência, a superestrutura de uma casa se ergue sobre a base em diferença e oposição a esta.

17 Aqui nós não vamos lidar com a questão do progresso no desenvolvimento para além da esfera humana. Contudo, é possível observar, com Lukács (2008, p. 345), que: "Evolução e retrocesso existem apenas sob um determinado ponto de vista. Se uma espécie de vida pode ou não vingar por meio de uma adaptação biológica, isso configura ou não um progresso apenas sob o ponto de vista desta espécie. Mas penso que o desenvolvimento global não tem nada que ver com isso: ele segue irreversivelmente, em última instância, de forma causal. Voltando ao homem: a adaptação biológica, que é uma adaptação passiva ao meio ambiente, é suplantada, com o trabalho humano, por uma adaptação ativa, que muda o meio ambiente". 
satisfação tende a existir uma gama cada vez maior de categorias puramente sociais. Finalmente, o terceiro momento que nos permite capturar o progresso em termos objetivos seria a formação da própria humanidade, do gênero humano como ser que existe não apenas em si, mas que é também para si. Pois a história universal pode (e deve) ser concebida ela mesma como um produto histórico. Foi só depois de um longo processo que a humanidade pôde se reconhecer, primeiro apenas em determinações particulares como tribos, comunidades, castas etc. até reconhecer-se como gênero. Apenas com a integração das comunidades humanas pelo mercado mundial há condições objetivas para o reconhecimento da humanidade em si como um universal, como tendo uma existência para nós.

Mas é também importante destacar que todas essas tendências que consubstanciam o progresso afirmam-se historicamente de modo contraditório. Foi através da guerra, da exploração e da degradação humana que o desenvolvimento das forças produtivas, o recuo das barreiras naturais e a formação do gênero humano puderam afirmar-se. Dito de outro modo, o progresso objetivo pode aparecer de modo alienado. Mas este é apenas outro aspecto do desenvolvimento desigual referido ao progresso em si mesmo, o seu caráter ineliminavelmente contraditório.

Entendido o problema dessa forma, a natureza contraditória do progresso confere um novo sentido teórico ao uso por Marx de termos como "bárbaro" ou "civilizado". Antes de tudo, note-se que o termo "bárbaro", aplicado às sociedades "asiáticas", tinha trânsito corrente - tanto no jargão popular, quanto em documento oficiais - no momento em que Marx escreve os já referidos artigos, e que estes se dirigiam para um público amplo. E não se pode negar que Marx era um homem de seu tempo, provavelmente compartilhando com seus contemporâneos muitas das crenças comuns àquela época. Não se pode esquecer também, entretanto, que Marx era principalmente um crítico de seu tempo, inclusas aí as crenças burguesas da sociedade vitoriana.

Assim, voltando às análises marxianas da política colonial, podemos ver o autor questionar-se sobre a possibilidade de os capitalistas ingleses "emanciparem e regenerarem as condições de vida da massa" na Índia, e concluir: o que eles "não falharão em fazer é lançar as premissas materiais para tal. E a burguesia alguma vez já fez mais que isso? Alguma vez ela já promoveu um progresso sem arrastar indivíduos e povos por sangue e sujeira, por miséria e degradação?" (Marx; Engels, 1979, v. 12, p. 221. 
Tradução e grifos nossos.) Aqui encontramos um exemplo inegável da concepção marxiana de progresso e desenvolvimento histórico desigual. Embora ele ainda esteja descrevendo um progresso - ou, mais precisamente, a possibilidade de um progresso - ele não se furta a reconhecer a tragédia social diretamente associada a este.

Da mesma forma seria possível creditar, de acordo com essa interpretação, aos termos "bárbaro" e "civilizado" um significado teórico bastante específico. O "bárbaro" significaria, então, qualquer condição que obstrui o desenvolvimento da humanidade - sendo o termo "civilizado", em contraste, guardado para condições que o permitem. No artigo "Revolution in China and in Europe", de 1853, por exemplo, Marx se refere ao "bárbaro e hermético isolamento" da China, destruído pela Inglaterra. Marx qualifica o isolamento como bárbaro porque ele obstrui o desenvolvimento do gênero humano, no sentido objetivo que discutimos anteriormente, restringindo a diversidade de relações e capacidades humanas, impedindo a tendência à conformação do gênero humano. Sob essa ótica, a sociedade capitalista ocidental era mais civilizada que os "bárbaros asiáticos" isolados em suas sociedades. Contudo, na passagem supracitada a condição bárbara refere-se exclusivamente ao isolamento chinês e não a uma condição geral extensiva por toda eternidade ao povo chinês.

Aliás, entendida a questão dessa forma, também fica claro por que Marx qualifica como "bárbaro" o capitalismo ocidental. Pois o capitalismo, embora progressista com relação a formações sociais pregressas, com seu desenvolvimento contraditório também obstrui a efetiva emancipação humana, na medida em que aprisiona a humanidade aos imperativos de seu próprio trabalho. Na medida em que cria condições para desenvolver suas potencialidades, mas também as restringe ou permite sua afirmação parcial apenas a uma parte da humanidade (às expensas da parte restante). ${ }^{18}$

Assim, é possível entender que a oposição entre o "barbarismo asiático" e a "civilização" capitalista ocidental adquire, por vezes, em Marx uma conotação obviamente irônica. Comentando um artigo do tratado sino-britânico de 1858, que proibia a utilização do termo "bárbaro" em documentos oficiais, Marx escreve com fina ironia:

18 Não casualmente Marx e Engels observam no Manifesto que a tarefa histórica da emancipação seria pôr, "no lugar da antiga sociedade burguesa, com as suas classes e antagonismos de classes (...) uma associação na qual o livre desenvolvimento de cada um é a condição para o livre desenvolvimento de todos" (Marx; Engels, 2010, p. 59). 
As autoridades chinesas se autoproclamando celestiais, quão humilde para sua compreensão não deve parecer John Bull que, ao invés de insistir em ser chamado de divino ou olimpico, contenta-se em arrancar o personagem representado pela palavra "bárbaro" dos documentos oficiais (Marx; Engels, 1979, v. 16, p. 49).

Já no artigo "Trade with China", Marx troca a oposição "mundo bárbaro" vs. "mundo civilizado" pela oposição "mundo bárbaro" vs. "mundo mercantil" e observa: "a carência de desejos e predileção por modos hereditários de vestir-se são obstáculos que o comércio civilizado encontra em todos os novos mercados" (Ibid., p. 537-538). E referindo-se ao domínio inglês na Índia, não se furta a relatar "a profunda hipocrisia e o barbarismo inerente à civilização burguesa que recorre a uma 'atroz rapacidade' na Índia" (Marx, 1979, v. 12, p. 221, grifos nossos).

É por isso que no Manifesto do partido comunista - uma das principais fontes daqueles que se interessam por afirmar um suposto preconceito marxiano contra as "comunidades bárbaras" - Marx e Engels colocam que o capitalismo "obriga à capitulação os bárbaros mais tenazmente hostis aos estrangeiros", apenas para afirmar na sequência que com isso "obriga todas as nações a adotarem o modo burguês de produção, constrange-as a abraçar a chamada civilização, isto é, a tornarem-se burguesas" (Marx; Engels, 2010, p. 44, grifos nossos).

\section{Conclusão}

A título de conclusão, voltemos à questão das "sociedades asiáticas" na perspectiva marxiana. Como vimos, Marx usou a categoria "modo de produção asiático" para tratar das condições estacionárias de certas sociedades. Usou também adjetivos como "não-históricos" ou "bárbaros" para tratar de algumas dessas sociedades. Pode-se concluir que haveria, então, um preconceito intrínseco à visão marxiana? Ao longo das últimas páginas, tentamos mostrar que não. Ao contrário, sustentamos nas seções anteriores que a não-historicidade atribuída a esses povos não tem um sentido teórico em Marx, isto é, que a condição estacionária das "sociedades asiáticas" é apenas relativa.

Argumentamos também que as observações de Marx sobre as sociedades "asiáticas" devem ser tratadas à luz de uma concepção mais ampla de progresso histórico, capaz de dar conta de suas contrações, de sua não linearidade e de seu caráter necessariamente desigual. Isso não apenas con- 
fere ao "barbarismo" dessas sociedades um novo sentido teórico como nos permite entender por que Marx as toma como "mais civilizadas" que o "Ocidente", em certos aspectos.

Nesse sentido, encerramos este artigo com algumas observações de Marx acerca da superioridade "asiática" sobre o "capitalismo ocidental". Examinando as possibilidades de regeneração social na Índia, Marx lista algumas características do povo indiano que indicam maior grau de desenvolvimento do que o dos povos europeus, por exemplo. Ele nota que a Índia, "cujos gentis nativos são, para usar a expressão do Príncipe Soltykov, plus fins et plus adroits que les Italiens", deixou "perplexos os oficiais britânicos por sua bravura" (Marx; Engels, 1979, v. 12, p. 221). Observa ainda que os indianos desenvolveram formas de consciência superiores às europeias, que se tornaram "a fonte de nossas línguas e religiões" (Ibid.).

Da mesma forma, ao analisar o comércio de ópio com a China, Marx destaca a posição eticamente superior dos chineses relativamente aos britânicos. Assim, embora critique a relação paternalista do imperador com o povo chinês, Marx não deixa de observar que essa relação ainda é eticamente superior ao "princípio pecuniário" que animava os capitalistas ingleses. Pois os ingleses eram movidos apenas pela preocupação em retirar lucros de seu comércio com a China, "à custa da vida humana e da moralidade" (Marx; Engels, 1979, v. 15, p. 234). O comércio de ópio contrapunha o "mundo antiquado" à "sociedade moderna" num duelo mortal, no qual o primeiro é "impulsionado por motivos éticos", enquanto o último "luta pelo privilégio de comprar nos mais baratos e vender nos mais caros mercados" (Marx; Engels, 1979, v. 16, p. 16).

\section{Referências}

ANDERSON, P. Linhagens do Estado absolutista. São Paulo: Unesp, 2016.

ARICÓ, J. Marx e a América Latina. Rio de Janeiro: Paz e Terra, 1982.

AUGUSTO, A. G. Modo de produção asiático: considerações teóricas à luz do debate historiográfico. Revista História Econômica \& História de Empresas, v. 18, n. 1, 2015.

HEGEL, G. W. F. Lectures on Logic. Bloomington: Indiana University Press, 2008.

HEINRICH, M. Engels' edition of the third volume of Capital and Marx's manuscripts. Science \& Society, v. 60, n. 4, p. 452-466, 1997.

HOBSBAWM, E. Como mudar o mundo: Marx e o marxismo, 1840-2011. São Paulo: Companhia das Letras, 2011. 
LÊNIN, V. I. O desenvolvimento do capitalismo na Rússia. São Paulo: Abril Cultural, 1983.

LÊNIN, V. I. O imperialismo: etapa superior do capitalismo. Campinas: FE/UNICAMP, 2011.

LUKÁCS, G. Der Spiegel entrevista o filósofo Lukács. Verinotio, n. 9, ano v, nov. 2008.

LUKÁCS, G. Para uma ontologia do ser social I. São Paulo: Boitempo Editorial, 2012.

MANDEL, E. A formação do pensamento econômico de Karl Marx: de 1843 até a publicação de O capital. Rio de Janeiro: Zahar, 1968.

MARX, K.; ENGELS, F. Collected Works. 50 v. New York: International Publishers, 1979.

MARX, K.; ENGELS, F. A ideologia alemã : crítica da mais recente filosofia alemã em seus representantes Feuerbach, B. Bauer e Stirner, e do socialismo alemão em seus diferentes profetas. São Paulo: Boitempo Editorial, 2007.

MARX, K.; ENGELS, F. Manifesto comunista. São Paulo: Boitempo Editorial, 2010.

MARX, K.; ENGELS, F. Luta de classes na Rússia. São Paulo: Boitempo Editorial, 2013.

MARX, K. O capital: crítica da economia política. L. III. São Paulo: DIFEL, 1987

MARX, K. Grundrisse. São Paulo: Boitempo Editorial, 2011.

MARX, K. O capital: crítica da economia política. L. I. São Paulo: Boitempo Editorial, 2013.

ROSDOLSKY, R. Engels and the 'Nonhistoric' Peoples: The National Question in the Revolution of 1848. Critique: Journal of Socialist Theory, 18 (special issue), 1991.

SAID, E. Orientalismo: o Oriente como invenção do Ocidente. São Paulo: Companhia das Letras, 2007.

TROTSKY, L. História da Revolução Russa. Paris: Edições Seuil, 1950. Disponível em: <https:// www.marxists.org/portugues/trotsky/1930/historia/>. Acesso em 20 abr. 2020.

\section{Sobre os autores}

André Guimarães Augusto - andreaugusto@id.uff.br

Departamento de Economia, Universidade Federal Fluminense, Niterói, Rio de Janeiro, Brasil.

ORCID: https://orcid.org/0000-0002-1077-2288.

Flávio Miranda - flavioferreiramiranda@hotmail.com

Universidade Federal Rural do Rio de Janeiro, Nova Iguaçu, Rio de Janeiro, Brasil.

ORCID: https://orcid.org/0000-0003-3524-0269.

Hugo F. Corrêa - hcorrea@id.uff.br

Departamento de Economia, Universidade Federal Fluminense, Niterói, Rio de Janeiro, Brasil.

ORCID: https://orcid.org/0000-0003-4687-243X.

\section{Sobre 0 artigo}

Recebido em 09 de outubro de 2018. Aprovado em 06 de maio de 2019. 